\title{
The Physiology of L-Methionine Catabolism to the Secondary Metabolite Ethylene by Escherichia coli
}

\author{
By N. SHIPSTON AND A. W. BUNCH* \\ Biological Laboratory, University of Kent, Canterbury, Kent CT2 $7 N J, U K$
}

(Received 22 August 1988; revised 23 January 1989; accepted 20 February 1989)

\begin{abstract}
Catabolism of L-methionine by Escherichia coli strain B SPAO led to the formation of ethylene as a secondary metabolite (ethylenogenesis). Methionine was initially deaminated by a transamination reaction to the 2-oxo acid 2-oxo-4-methylthiobutyric acid (KMBA) which was then converted to ethylene. The utilization of L-methionine as an additional nitrogen source was investigated by examining ethylene synthesis under different nitrogen supply conditions. Ethylene formation in batch culture was unaffected by the concentration of the precursor L-methionine in the medium although increasing concentrations of $\mathrm{NH}_{4} \mathrm{Cl}$ resulted in progressively less ethylene formation. Cultures grown without L-methionine did not produce ethylene but were able to synthesize ethylene when L-methionine or KMBA was provided. Addition of L-tyrosine to batch cultures reduced the yield of ethylene after $42 \mathrm{~h}$ by $54 \%$. Under these conditions the maximum transient level of KMBA was reduced by $32 \%$ and occurred later compared to when L-methionine was the only amino acid supplement. Continuous cultures grown under ammonia limitation produced both ethylene and KMBA. In contrast, when glucose was limiting, neither of these metabolites were produced. Cells harvested from continuous cultures grown under glucose or ammonia limitation were able to synthesize ethylene from either L-methionine or KMBA although their capacity for ethylene synthesis (ethylenogenic capacity) was optimal under ammonia limitation $(C: N$ ratio $=20)$.
\end{abstract}

\section{INTRODUCTION}

Microbial secondary metabolism is one of the most poorly understood and characterized areas of biochemistry. However, it is responsible for the synthesis of many important biologically derived products such as antibiotics, and flavour and fragrance compounds. As the biochemical mechanisms underlying these systems are unknown, methods for their manipulation have few rational guidelines (Bunch \& Harris, 1986). Therefore, there is a need to investigate the interaction of primary and secondary metabolic processes within cells, coupled with a detailed examination of the enzymes involved.

Ethylene formation (ethylenogenesis) by Escherichia coli exhitits many characteristics shared by other secondary metabolic processes (Ince \& Knowles, 1985; Primrose, 1977) and its synthesis from L-methionine occurs by a different pathway to that used by plants (Adams \& Yang, 1981). The first step appears to involve a soluble aminotransferase which produces 2-oxo4-methylthiobutyrate (KMBA) from L-methionine. The enzyme can use a variety of 2-oxo acids as the co-substrate but shows highest activity with 2-oxoglutarate. Bacteria grown in a defined medium containing glucose, $\mathrm{NH}_{4} \mathrm{Cl}$ and mineral salts supplemented with $\mathrm{L}$-methionine excrete $\mathrm{KMBA}$ which accumulates in the culture fluid prior to ethylene production (Billington et al., 1979; Ince \& Knowles, 1985). The specific activity of the L-methionine aminotransferase does not change during growth of $E$. coli in batch culture (Ince \& Knowles, 1986). Ethylene production is reportedly influenced by glucose and ammonia levels and ethylenogenesis may be

Abbreviations: KMBA, 2-oxo-4-methylthiobutyric acid; 2,4-DNP, 2,4-dinitrophenylhydrazone. 
involved in the recovery of the amino group of L-methionine when there is a surplus of this amino acid in the medium (Ince \& Knowles, 1986). It is notable that $E$. coli possesses high and low affinity systems for the uptake of exogenous L-methionine (Kadner \& Watson, 1974).

The objective of this study was to examine the relationship between ethylene formation in $E$. coli and the amount and type of nitrogen source present in the culture medium.

\section{METHODS}

Organisms and growth conditions. Escherichia coli strain B SPAO, obtained from Dr C. S. Dow (University of Warwick), was maintained on nutrient agar slants $(2.8 \%$, w/v, Oxoid Nutrient Agar) at room temperature and subcultured at monthly intervals. The defined liquid medium used for growth and ethylene formation was described by Ince and Knowles (1985). Glucose and $\mathrm{NH}_{4} \mathrm{Cl}$ concentrations were varied and additional amino acids added as indicated in the text. All amino acid solutions were sterilized by filtration through a $0.45 \mu \mathrm{m}$ filter (Whatman). Growth was estimated by measuring the optical density of culture at $540 \mathrm{~nm}$ using an LKB 4049 spectrophotometer.

Cultures grown on orbital shakers were either in $250 \mathrm{ml}$ or 2 litre Erlenmeyer flasks containing $30 \mathrm{ml}$ and $500 \mathrm{ml}$ of liquid growth medium respectively. Serum caps (Subaseal, Fisons) were fitted to flasks to prevent the loss of ethylene. This has not been found to result in oxygen limitation (J. E. Ince \& C. J. Knowles, unpublished observations). Bacteria were grown at $36{ }^{\circ} \mathrm{C}$ and 200 r.p.m. Inocula were prepared by washing bacteria from a nutrient agar slant into $100 \mathrm{ml}$ of growth medium in a $250 \mathrm{ml}$ Erlenmeyer flask. This culture was then grown for $24 \mathrm{~h}$ under the conditions described above and a $2 \%(\mathrm{v} / \mathrm{v})$ inoculum added to experimental flasks.

Continuous culture was done in a 1 litre fermenter (LH 500 Series) with a working volume of $800 \mathrm{ml}$. The defined medium described for batch cultures were used but glucose and $\mathrm{NH}_{4} \mathrm{Cl}$ concentrations were varied in order to achieve nitrogen- or carbon-limiting growth conditions. L-Methionine was added where stated. A $2 \%$ (v/v) inoculum was used and the culture was stirred at 1000 r.p.m. Temperature was maintained at $36^{\circ} \mathrm{C}$ and the $\mathrm{pH}$ at 6.90 by the automatic addition of $2 \mathrm{M}-\mathrm{NaOH}$. An air flow rate of 1 litre $\mathrm{min}^{-1}$ was sufficient to maintain the dissolved oxygen tension at $80-95 \%$ saturation. The organism was initially cultivated under batch conditions. After $12 \mathrm{~h}$ a continuous nutrient feed was delivered by peristaltic pump (P-1, Pharmacia) and the culture allowed to reach steady-state at a growth rate (dilution rate) of $0.1 \mathrm{~h}^{-1}$. Ethylene in the fermenter gas outlet was absorbed and concentrated using a mercuric perchlorate trapping system as described by Lynch \& Harper (1974).

Analytical methods. Ethylene samples were analysed by gas chromatography using the conditions described by Ince \& Knowles (1985). Glucose and ammonia were also measured as described previously (Ince \& Knowles, 1985).

Amino acids were converted to their $O$-phthaldialdehyde (OPA) derivatives by the method of Gardner \& Miller (1980) and identified using reversed-phase HPLC. OPA-amino acids were separated on a reverse-phase column (Spherisorb ODS-2, $5 \mu \mathrm{m} ; 250 \times 4.6 \mathrm{~mm}$ internal diameter; Jones chromatography) attached to a Milton Roy HPLC apparatus. Aqueous samples $(10 \mu \mathrm{l})$ were filtered to $0.2 \mu \mathrm{m}$, injected onto the column and eluted isocratically at a flow rate of $1 \mathrm{ml} \mathrm{min}{ }^{-1}$ using a mobile phase of methanol $/ 0.05 \mathrm{M}-\mathrm{KH}_{2} \mathrm{PO}_{4}$ (adjusted to $\mathrm{pH} 4.5$ with $\mathrm{HCl}$ )/water $(55: 20: 25$, by vol.). The OPA-amino acids were detected using a spectrofluorimetric detector (excitation maximum $355 \mathrm{~nm}$; emission maximum $390 \mathrm{~nm}$ ).

Free 2-oxo acids are unstable in aqueous environments and detection of individual 2-oxo acids on mixtures is frequently difficult. A method based on that of Hemming \& Gubler (1979) was adopted whereby 2-oxo acids are converted to their 2,4-dinitrophenylhydrazones (2,4-DNPs), followed by separation and detection using pairedion reverse-phase HPLC. The 2,4-DNPs of the 2-oxo acids were prepared at room temperature as follows: $100 \mu 1$ of freshly prepared 2,4-dinitrophenylhydrazine $(0.2 \%, \mathrm{w} / \mathrm{v})$ in $2 \mathrm{M}-\mathrm{HCl}$ was added to $100 \mu \mathrm{l}$ of a solution containing 2-oxo acids and allowed to react for $30 \mathrm{~min}$. Insoluble hydrazones, visible as yellow precipitates, and unreacted 2,4-dinitrophenylhydrazine were then extracted into $500 \mu 1$ ethyl acetate. Vigorous mixing was necessary for the complete extraction which left the aqueous phase almost colourless. Solvent was removed under a stream of air leaving a yellow residue which was stored at $4{ }^{\circ} \mathrm{C}$ until required. The residue was dissolved in methanol, samples $(10 \mu \mathrm{l})$ injected onto the HPLC column and hydrazone derivatives eluted isocratically at a flow rate of $0.5 \mathrm{ml} \mathrm{min}^{-1}$ with methanol $/ 0.05 \mathrm{M}$-tetrabutylammonium hydroxide (adjusted to $\mathrm{pH} 4.3$ with glacial acetic acid) $(80: 20, \mathrm{v} / \mathrm{v})$. Separated 2,4-DNPs were detected at $368 \mathrm{~nm}$ and peak data evaluated using a Milton Roy integrator/printer-plotter.

Standards for HPLC were prepared using authentic L-amino acids and 2-oxo acids without further purification.

Ethylene assays with harvested bacteria. Bacteria were harvested from cultures by centrifugation $(20000 \mathrm{~g}$, $10 \mathrm{~min}, 4^{\circ} \mathrm{C}$ ), washed in $20 \mathrm{mM}-\mathrm{Na}_{2} \mathrm{HPO}_{4} / \mathrm{KH}_{2} \mathrm{PO}_{4}$ buffer $(\mathrm{pH} 7.0)$ at $4{ }^{\circ} \mathrm{C}$ and resuspended in the same phosphate buffer to about $15 \mathrm{mg}$ dry weight $\mathrm{ml}^{-1}$. Culture samples never exceeded $10 \%(\mathrm{v} / \mathrm{v})$ of the total culture volume. Bacterial suspension $(1.0 \mathrm{ml})$ was added to a $25 \mathrm{ml}$ Erlenmeyer flask fitted with a serum cap and 
containing the following assay mixture: $20 \mathrm{~mm}-\mathrm{Na}_{2} \mathrm{HPO}_{4} / \mathrm{KH}_{2} \mathrm{PO}_{4}, 0 \cdot 1 \mathrm{~mm}-\mathrm{CaCl}_{2}, 1 \cdot 0 \mathrm{mM}-\mathrm{MgSO}_{4}$, trace elements (as for growth), $10 \mathrm{~mm}$-glucose and $10 \mathrm{mM}-\mathrm{L}-\mathrm{methionine}$ or $10 \mathrm{mM}-\mathrm{KMBA}$ in a total volume of $1 \mathrm{ml}$. Flasks were incubated at $37^{\circ} \mathrm{C}$ in the dark on an orbital shaker operating at 200 r.p.m. Gaseous headspace samples $(0.5 \mathrm{ml})$ were removed from the flasks at $30 \mathrm{~min}$ intervals for $5 \mathrm{~h}$ using a gas-tight syringe and the ethylene content determined by gas chromatography.

The rate of ethylene synthesis by harvested bacterial cells is referred to as the ethylenogenic capacity (Ince $\&$ Knowles, 1985).

Radioassay of L-methionine aminotransferase in the soluble fraction of cell-free extracts (high-speed supernatant). High speed supernatant was prepared as described previously (Ince \& Knowles, 1986). Reaction mixtures $(100 \mu \mathrm{l})$ contained: $50 \mathrm{~mm}$-Tris $/ \mathrm{HCl}(\mathrm{pH} 8 \cdot 0), 250 \mu \mathrm{M}$-pyridoxal 5'-phosphate, $10 \mathrm{~mm}-\mathrm{L}-\left[\mathrm{U}-{ }^{14} \mathrm{C}\right]$ methionine $(0 \cdot 064 \mu \mathrm{Ci}$ $\mu \mathrm{mol}^{-1} ; 2370 \mathrm{~Bq} \mathrm{ml}{ }^{-1}$ ), $24 \mu \mathrm{g}$ bovine serum albumin, $5 \mathrm{~mm}$-2-oxoglutarate and $40 \mu \mathrm{l}$ of high speed-supernatant.

After $10 \mathrm{~min}$ incubation at $37^{\circ} \mathrm{C}$, the reaction was stopped with $0.3 \mathrm{ml} 1 \mathrm{M}-\mathrm{HCl}$ followed by addition of ethyl acetate/toluene $(4: 1, v / v)$. Under these acidic conditions the 2-oxo acids are extracted into the organic solvent whilst amino acids remain in the aqueous layer. Samples $(100 \mu \mathrm{l})$ of the organic phase were combined with $4 \mathrm{ml}$ of Optiphase $\mathrm{T}$ liquid scintillant and radioactivity was determined by scintillation counting (Beckman LS7800).

Protein was estimated by the method of Bradford (1976) using bovine serum albumin as a standard.

Reproducibility of results. All batch culture experiments and harvested cell ethylene assays were done in triplicate; the results given in Figs 1, 2 and 4 are means of these measurements.

Materials. L-[U-1 $\left.{ }^{14} \mathrm{C}\right]$ methionine was obtained from Amersham. Optiphase T scintillation fluid was purchased from LKB and tetrabutylammonium hydroxide from Aldrich. All other chemicals were purchased from Sigma. Solvents were of AR grade (May \& Baker or Fisons). Glass distilled water was used throughout.

\section{RESULTS}

\section{Effect of different ammonia concentrations on ethylenogenesis in batch cultures}

E. coli was grown in defined medium supplemented with $2.7 \mathrm{mM}-\mathrm{L}-\mathrm{methionine}$. Growth and ethylene production in cultures with various initial concentrations of $\mathrm{NH}_{4} \mathrm{Cl}$ were determined for $30 \mathrm{~h}$ (Fig. 1a,b). Growth yields were only slightly different over a range of $\mathrm{NH}_{4} \mathrm{Cl}$ concentrations used. Growth was slower when no $\mathrm{NH}_{4} \mathrm{Cl}$ was present and when methionine was

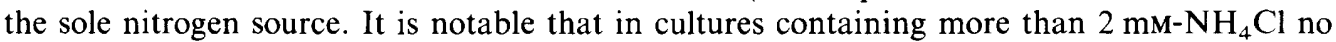
residual glucose could be detected after $30 \mathrm{~h}$.

After $30 \mathrm{~h}$ ethylene production was highest in cultures containing $2.0 \mathrm{~mm}-\mathrm{NH}_{4} \mathrm{Cl}$. Above this concentration progressively less ethylene accumulated in spite of similar growth yields. After $17 \mathrm{~h}$ incubation all cultures were producing ethylene. Bacteria harvested from cultures at this time showed different ethylenogenic capacities (Fig. 2). Interestingly, their ethylenogenic capacity was inversely proportional to the initial concentration of $\mathrm{NH}_{4} \mathrm{Cl}$ in the growth medium.

\section{Effect of different L-methionine concentrations on ethylenogenesis in batch cultures}

E. coli was grown for $15 \cdot 5 \mathrm{~h}$ in defined liquid medium initially containing $0 \cdot 5,1 \cdot 0,2 \cdot 0,2 \cdot 5$ or $3.0 \mathrm{mM}-\mathrm{L}-\mathrm{methionine}$. The glucose concentration was initially $10 \mathrm{mM}$ and that of $\mathrm{NH}_{4} \mathrm{Cl} 3.0 \mathrm{mM}$. There was no difference in the growth rate (doubling time $2 \mathrm{~h}$ ) and the final cell yield was the same in each culture $\left(\mathrm{OD}_{540}\right.$ after $15.5 \mathrm{~h}$ was $\left.1.02 \pm 0 \cdot 056\right)$. Ethylene was present in all flasks after $10 \mathrm{~h}$ and all cultures produced ethylene at a similar rate $(0.107 \pm 0.0176 \mu \mathrm{mol}$ per flask $)$ to the culture grown at 3.0 mM- $\mathrm{NH}_{4} \mathrm{Cl}$ (Fig. 2) except that no ethylene production was seen in the absence of methionine. After $15.5 \mathrm{~h}$, the ethylene yield of the cultures was $0.029 \pm 0.0063 \mu \mathrm{mol}$ $(\mathrm{mg} \text { cell dry wt })^{-1}$. Harvested, washed cells, including those grown without L-methionine, all had similar ethylenogenic capacities $\left[4.73 \pm 1.17 \mathrm{nmol} \mathrm{h}^{-1}(\mathrm{mg} \text { cell dry wt })^{-1}\right]$.

\section{Ethylenogenesis in ammonia- and glucose-limited continuous culture in the presence and absence of L-methionine}

Fig. 3 shows the residual concentrations of glucose and $\mathrm{NH}_{4} \mathrm{Cl}$ and ethylenogenic capacities of bacteria harvested from continuous cultures grown over a range of carbon : nitrogen ratios $(\mathrm{C}: \mathrm{N})$ from 2 to 60 . Cultures were ammonia limited above a $\mathrm{C}: \mathrm{N}$ of 12 . Harvested bacteria exhibited the highest ethylenogenic capacity with L-methionine or KMBA as a substrate when 

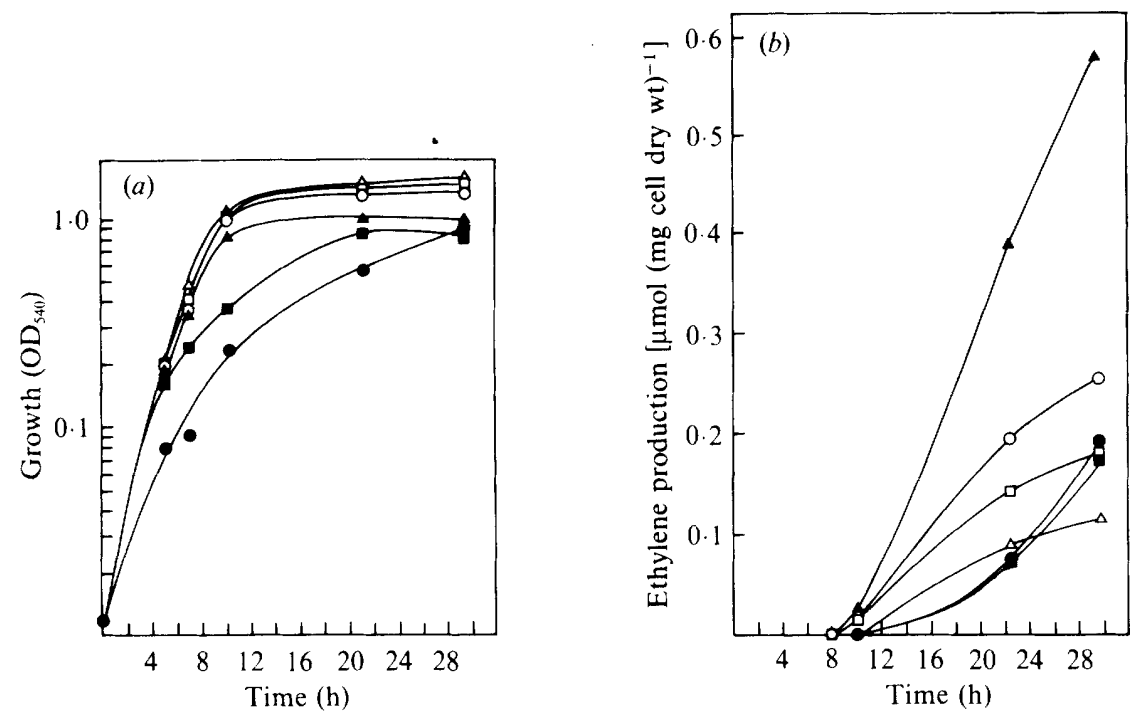

Fig. 1. Growth (a) and ethylene formation $(b)$ by $E$. coli B SPAO in medium containing 10 mM-glucose, $2.7 \mathrm{mM}$-L-methionine and concentrations of $\mathrm{NH}_{4} \mathrm{Cl}$ as follows: $0(\mathbf{O}), 0.5(\mathbf{D}), 3.0(\mathbf{\Delta}), 6.0(\mathrm{O}), 10(\square)$ and $20 \mathrm{~mm}(\triangle)$. Bacteria were grown in $250 \mathrm{ml}$ Erlenmeyer flasks (culture volume $30 \mathrm{ml}$ ). For comparison, ethylene production is expressed in $\mu \mathrm{mol}(\mathrm{mg} \text { cell dry } \mathrm{wt})^{-1}$.

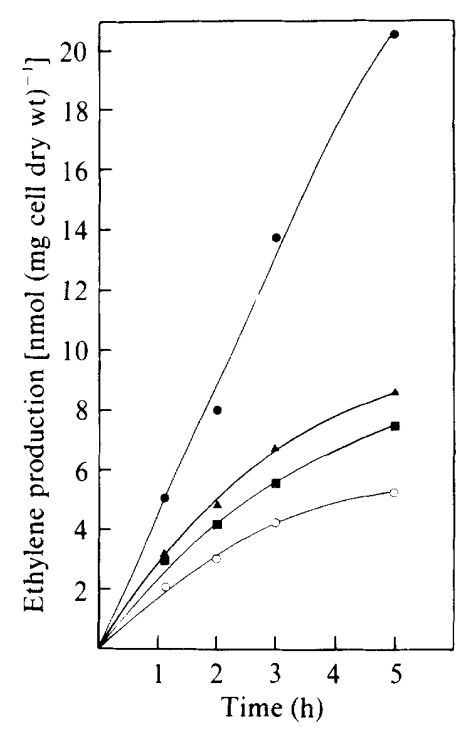

Fig. 2. Ethylenogenic capacity of E. coli B SPAO grown in medium containing $10 \mathrm{~mm}$-glucose, $2 \cdot 7 \mathrm{M}$-Lmethionine and concentrations of $\mathrm{NH}_{4} \mathrm{Cl}$ as follows: $0.5(\mathcal{O}), 3.0(\boldsymbol{\Delta}), 10(\boldsymbol{\square})$ and $20 \mathrm{mM}(\mathrm{O})$. Bacteria were grown in 2 litre Erlenmeyer flasks (culture volume $500 \mathrm{ml}$ ) and harvested after $17 \mathrm{~h}$, corresponding to the end of exponential growth. Washed cell suspensions were assayed for the ability to form ethylene from L-methionine as indicated in the text.

cultures were grown under conditions of ammonia limitation at a $\mathrm{C}: \mathrm{N}$ of 20 (glucose $10 \mathrm{mM}$, $\mathrm{NH}_{4} \mathrm{Cl} 3 \mathrm{~mm}$, no L-methionine). The rate of ethylene synthesis by non-growing cell suspensions was at least 10 -fold higher when KMBA was the assay substrate rather than L-methionine over the range of carbon: nitrogen ratios tested. 


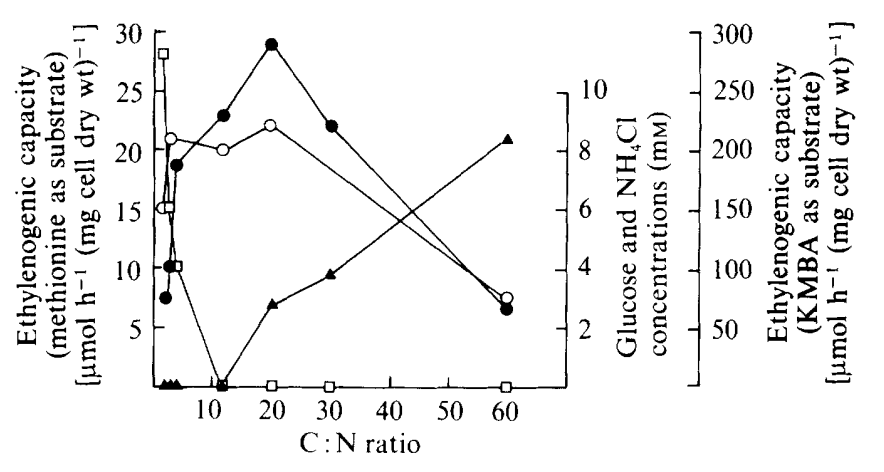

Fig. 3. Ethylenogenic capacity of E. coli B SPAO growing in continuous culture as a function of the $C: N$ ratio of the inflowing medium. Bacteria were grown in a fermenter $(800 \mathrm{ml}$ working volume), stirred continuously at 1000 r.p.m. The temperature was $36^{\circ} \mathrm{C}$ and a pH of 6.9 was maintained by the automatic addition of $2 \mathrm{M}-\mathrm{NaOH}$. An air flow rate of 1 litre $\mathrm{min}^{-1}$ was sufficient to aerate the cultures. The organism was initially cultivated under batch conditions. After $12 \mathrm{~h}$ a continuous nutrient feed $\left(80 \mathrm{ml} \mathrm{h}^{-1}\right)$ was delivered by a peristaltic pump and the culture allowed to reach steady-state at a growth rate (dilution rate) of $0 \cdot 1 \mathrm{~h}^{-1}$. Essentially, the defined medium described by Ince \& Knowles (1985) was used and different $\mathrm{C}: \mathrm{N}$ ratios were obtained by varying the concentration of $\mathrm{NH}_{4} \mathrm{Cl}$ at a fixed concentration of $10 \mathrm{~mm}$-glucose. Samples $(50 \mathrm{ml})$ of culture were removed at intervals from the fermenter and bacteria were harvested, washed and assayed for their ability to form ethylene from $\mathrm{L}$ methionine (O) and KMBA (O). Concentrations of glucose $(\boldsymbol{\Lambda})$ and $\mathrm{NH}_{4} \mathrm{Cl}(\square)$ in samples of culture supernatant were recorded.

When L-methionine was added at a final concentration of $2.7 \mathrm{mM}$ to the continuous culture at steady-state under ammonia limitation $(C: N=30)$, ethylene was present in the effluent gas from the fermenter and KMBA and 2-oxoglutarate were detected in the culture medium. In glucose-limited cultures $(C: N=2)$ containing $L$-methionine no ethylene could be detected and neither KMBA nor 2-oxoglutarate accumulated in the culture medium. Although growth was not significantly affected by the presence of L-methionine ethylene was not produced when Lmethionine was absent from the growth medium.

Supplementing the culture medium with selected amino acids and its effect on ethylene production

L-Methionine uptake by batch cultures of $E$. coli is highest after ammonia present in the growth medium has been completely utilized (Ince \& Knowles, 1985). The aminotransferases present in $E$. coli enable it to utilize many amino acids as carbon and nitrogen sources. The enzymes have broad and overlapping substrate specificities (Jensen \& Calhoun, 1981) and the possibility that other amino acids might compete with or regulate 'methionine aminotransferase' activity, and hence ethylenogenesis, was investigated.

Amino acids tested were selected on the basis that they are known substrates for the aminotransferases of $E$. coli and were added individually with L-methionine to the defined medium at the concentrations specified.

Growth and ethylene production were similar in batch cultures grown on $10 \mathrm{~mm}$-glucose and $3 \mathrm{mM}-\mathrm{NH}_{4} \mathrm{Cl}$ containing $2.7 \mathrm{mM}$-L-methionine or $2.7 \mathrm{mM}-\mathrm{L}$-methionine supplemented with $3.0 \mathrm{mM}$-L-alanine, L-aspartate, L-glutamate, L-glutamine, L-isoleucine, L-leucine or L-valine. L-Tyrosine ( $2.0 \mathrm{mM}$ ), although not affecting growth (Fig. $4 a, b)$ reduced the yield of ethylene after $42 \mathrm{~h}$ by $54 \%$. The maximum transient level of $\mathrm{KMBA}$ was also reduced by $32 \%$ in the presence of L-tyrosine and occurred later compared to when tyrosine was absent.

The 2-oxo acid $p$-hydroxyphenylpyruvate was observed to accumulate in the medium and the time of its maximum appearance coincided with that for KMBA. High levels of $p$-hydroxyphenylpyruvate accumulated in medium containing both L-methionine and L-tyrosine (Fig. $4 b$ ). No ethylene accumulated in flasks containing only L-tyrosine. 


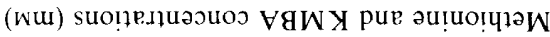

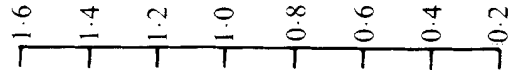

(wu) Uo!nk.
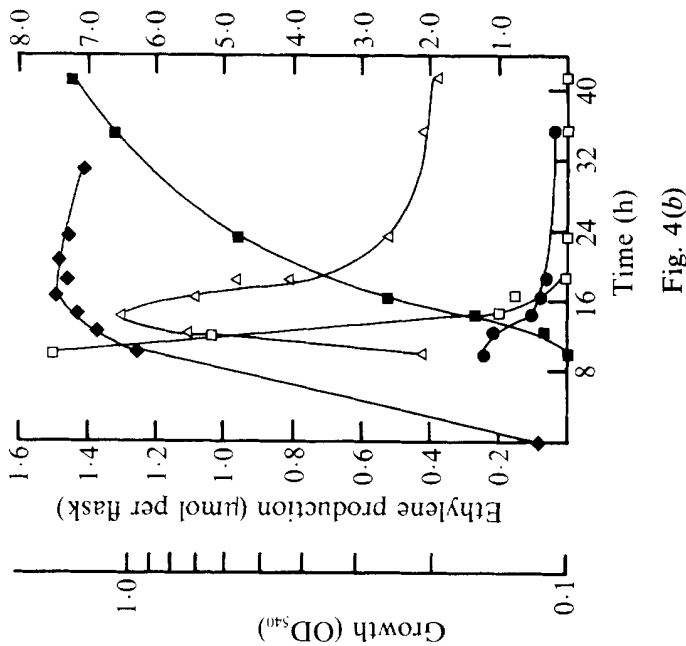

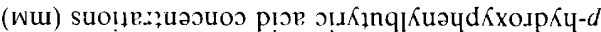
pup $\forall$ gW

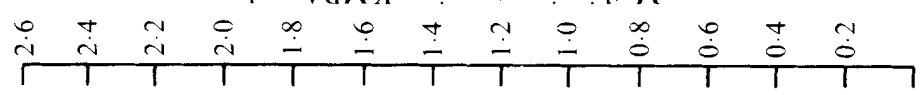

(wu) นo!penuวouos วsosn!D

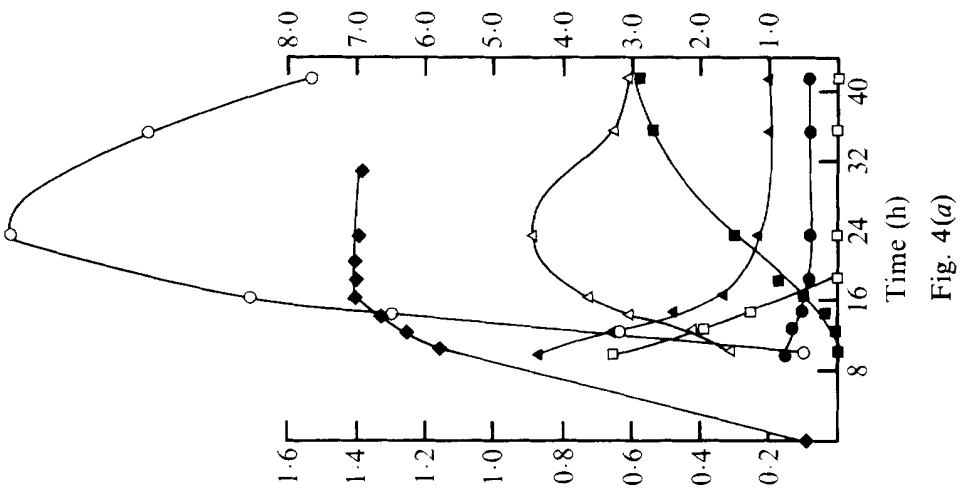

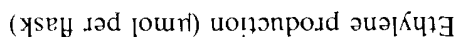

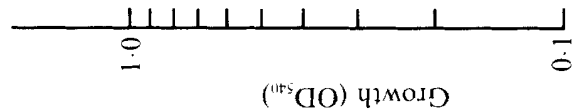


Repression of methionine aminotransferase activity by L-methionine and L-tyrosine

High-speed supernatants were prepared from cultures $(500 \mathrm{ml})$ harvested after exponential growth $(14 \mathrm{~h})$ in defined medium containing glucose $(10 \mathrm{mM}), \mathrm{NH}_{4} \mathrm{Cl}(3 \mathrm{mM})$ and L-methionine $(2.7 \mathrm{~mm})$, tyrosine $(2.0 \mathrm{mM})$ or L-methionine $(2.7 \mathrm{mM})$ and L-tyrosine $(2.0 \mathrm{mM})$. Methionine and tyrosine reduced the specific activity of methionine aminotransferase by $32 \%$ and $44 \%$ respectively compared to a specific activity of $3.17 \mu \mathrm{mol} \mathrm{h}^{-1}$ (mg protein) ${ }^{-1}$ which was obtained when no amino acid supplement was made. In combination, the two amino acids repressed aminotransferase activity by $65 \%$.

\section{DISCUSSION}

Many bacteria and fungi are able to synthesize ethylene (Primose, 1979). The most prolific ethylene producer so far identified, E. coli strain B SPAO, was the subject of this study. Ethylene, $\mathrm{CO}_{2}$ and methanethiol are produced from L-methionine by $E$. coli via the transamination of L-methionine to KMBA (Ince \& Knowles, 1986). It was suggested by Ince \& Knowles (1986) that ethylenogenesis by $E$. coli might enable scavenging of the amino group of methionine as a source of nitrogen when other sources are unavailable.

The assimilation of ammonia by E. coli is well-documented (Brown et al., 1974; Brown, 1976) but little information is available concerning growth on mixed nitrogen sources (Harder \& Dijkhuizen, 1976). In batch culture ethylene synthesis from the precursor L-methionine was influenced by the initial concentration of ammonia in the growth medium (Fig. 1). Further metabolism of ethylene by this organism has not been reported (S. Mansouri \& A. W. Bunch, unpublished results). Thus these differences must reflect the ability of the bacterium to synthesize ethylene. The ethylenogenic capacity of intact bacteria harvested at the end of the exponential growth phase $(17 \mathrm{~h})$ was inversely proportional to the initial concentration of $\mathrm{NH}_{4} \mathrm{Cl}$ in the growth medium.

When L-methionine was added to a continuous culture of $E$. coli maintained at a growth rate of $0 \cdot 1 \mathrm{~h}^{-1}$ under ammonia limitation, ethylene was synthesized and KMBA and 2-oxoglutarate were excreted into the culture fluid. The rate-limiting step in the dissimilation of L-methionine to ethylene appears to be the conversion of KMBA to ethylene, which would account for the accumulation of the KMBA in the culture fluid (see also Fig. 4).

Methionine is utilized as a sole nitrogen source which results in a lower growth rate (Fig. 1). It is apparent that methionine transamination occurs towards the end of the exponential growth phase and is followed by the slower conversion of KMBA to ethylene during the stationary phase (Fig. 4). L-Methionine aminotransferase activity is present throughout growth even in the absence of L-methionine (Ince \& Knowles, 1986).

In the presence of excess ammonia the principal mechanism for ammonia assimilation is via the reductive amination of 2-oxoglutarate catalysed by glutamate dehydrogenase (Kavanagh \& Cole, 1976). This may result in a lower availability of 2-oxoglutarate which is a cosubstrate for methionine dissimilation by the transamination reaction. At intracellular ammonia concentrations below $1 \mathrm{~mm}$ (Sakamoto et al., 1975) the glutamine synthetase/glutamate synthase assimilatory mechanism is stimulated. Provided the carbon source is abundant, a high intracellular concentration of 2-oxoglutarate is maintained (Neijssel \& Tempest, 1979) in order to saturate glutamate synthase for optimum activity (Hueting \& Tempest, 1979). These conditions may also favour the transamination reaction as an additional nitrogen salvage reaction and would explain the absence of ethylene, KMBA and 2-oxoglutarate as metabolic products when L-methionine is added to a glucose-limited continuous culture.

Cells harvested from continuous cultures grown in the absence of methionine were able to synthesize ethylene when methionine was added to harvested cells. The highest ethylenogenic capacity was shown by cells grown under ammonium limitation ( $C: N=20$, Fig. 3). Ethylene formation in batch culture was independent of the L-methionine concentration over the range $0 \cdot 5-3.0 \mathrm{mM}$, although L-methionine is reported to inhibit the activity of the methionine transport systems (Kadner, 1977). These observations support the suggestion that the primary function of the ethylene-forming enzymes may not be for ethylene synthesis. 
An alternative route of L-methionine dissimilation, which does not yield ethylene, may exist. For example, methionine $\gamma$-lyase, which is induced by L-methionine has been characterized in Pseudomonas spp. (Tanaka et al., 1976; Ito et al., 1976). The possibility that this activity is also present in $E$. coli is currently under investigation.

Thus physiological circumstances, particularly the nitrogen supply, may favour initial dissimilation of methionine by the aminotransferase route and subsequent conversion of KMBA to ethylene, either by influencing the levels of a precursor necessary for ethylene synthesis (e.g. 2-oxoglutarate) or by favouring an alternative route of L-methionine dissimilation.

The presence of ammonia can also affect uptake of amino acids by repressing the synthesis of specific permeases although this has not been reported for L-methionine (Kustu et al., 1979).

Supplementing the batch culture medium with other amino acids in addition to L-methionine showed that L-tyrosine lowered ethylene production, an effect which could not be attributed to differences in biomass (Fig. 4). This suggests that L-tyrosine either represses the synthesis of the ethylene-forming enzyme(s) or can compete as a substrate, probably for the transamination reaction, since $p$-hydroxyphenylpyruvate is observed to accumulate in batch culture (Fig. 4). The presence of two multispecific tyrosine aminotransferases in $E$. coli, one of which is tyrosine repressible, is well-documented (Collier \& Kohlaw, 1972; Gelfand \& Steinberg, 1977; Powell \& Morrison, 1978).

The results presented in this paper have shown that the cellular activity of the ethylenogenic enzymes is influenced by the availability of ammonia in the growth medium. However, this may not represent a direct involvement of the ethylenogenic system with nitrogen recovery from methionine. Indeed, it is possible that ethylenogenesis has no metabolic role but arises as a fortuitous combination of reactions brought about by non-specific enzymes whose main metabolic functions lie elsewhere. We are currently investigating this possibility.

N.S. wishes to acknowledge the SERC for their support. We would also like to thank Dr S. Mansouri, Dr J. E. Ince and Professor C. J. Knowles for many useful discussions and Ms S. Davies for typing this manuscript.

\section{REFERENCES}

Adams, D. D. \& YANG, S. F. (1981). Ethylene the gaseous plant hormone: mechanism and regulation of biosynthesis. Trends in Biochemical Sciences 6, 161-164.

Billington, D. C., Golding, B. T. \& Primrose, S. B. (1979). Biosynthesis of ethylene from methionine. Biochemical Journal 182, 827-836.

BRADFORD, M. M. (1976). A rapid and sensitive method for the quantitation of microgram quantities of protein utilizing the principle of protein-dye binding. Analytical Biochemistry 72, 248-254.

Brown, C. M. (1976). Nitrogen and metabolism in bacteria and fungi. In Continuous Culture, vol. 6, Applications and New Fields, pp. 277-314. Edited by A. C. R. Dean, D. C. Ellwood, C. G. T. Evans \& J. Melling. London: Ellis Horwood/Society for Chemical Industry.

Brown, C. M., MacDonald-Brown, D. S. \& Meers, J. L. (1974). Physiological aspects of microbial inorganic nitrogen metabolism. Advances in Microbial Physiology 114, 1-52.

BuNCH, A. W. \& HarRIS, R. (1986). The manipulation of microorganisms for the production of secondary metabolites. In Biotechnology and Genetic Engineering Reviews, pp. 117-144. Edited by G. E. Russell. Newcastle, UK : Intercept.
Collier, R. H. \& Kohlaw, G. (1972). Non-identity of the aspartate and the aromatic aminotransferase components of transaminase A in Escherichia coli. Journal of Bacteriology 112, 365-371.

Gardner, W. S. \& Miller, W. H. (1980). Reverse phase liquid chromatographic analysis of amino acids after reaction with $O$-phthalaldialdehyde. Analytical Biochemistry 101, 61-65.

Gelfand, D. H. \& Steinberg, R. A. (1977). Escherichia coli mutants defective in the aspartate and aromatic amino acid aminotransferases. Journal of Bacteriology 130, 429-440.

Harder, B. C. \& Dijkhuizen, L. (1976). Mixed Substrate Utilisation. In Continuous Culture, vol. 6, Applications and New Fields, pp. 277-314. Edited by A. C. R. Dean, D. C. Ellwood, C. G. T. Evans \& J. Melling. London: Ellis Horwood/Society for Chemical Industry.

Hemming, B. C. \& Gubler, C. J. (1979). High-pressure liquid chromatography of $\alpha$-keto acid 2,4-dinitrophenylhydrazones. Analytical Biochemistry 92, 3140.

Hueting, S. \& Tempest, D. W. (1979). Influence of the glucose input concentration on the kinetics of metabolite production by Klebsiella aerogenes NCTC 418 growing in chemostat culture in potas- 
sium- or ammonia-limited environments. Archives of Microbiology 123, 189-194.

INCE, J. E. \& KNowles, C. J. (1985). Ethylene formation by cultures of Escherichia coli. Archives of Microbiology 141, 209-213.

INCE, J. E. \& KNowles, C. J. (1986). Ethylene formation by cell free extracts of Escherichia coli. Archives of Microbiology 146, 151-158.

Ito, S., Nakamura, T. \& Eguchi, Y. (1976). Purification and characterisation of methioninase from Pseudomonas putida. Journal of Biochemistry 79, 1263-1272.

Jensen, R. A. \& Colhoun, D. H. (1981). Intracellular roles of microbial aminotransferases: overlap enzymes across different biochemical pathways, CRC Critical Reviews in Microbiology 89, 229-266.

KADNER, R. J. (1977). Transport and utilization of D-methionine and other methionine sources in Escherichia coli. Journal of Bacteriology 129, 207-216.

KaDNER, R. J. \& Watson, W. J. (1974). Methionine transport in Escherichia coli: physiological and genetic evidence for two uptake systems. Journal of Bacteriology 119, 401-409.

KaVANAGH, B. M. \& COLE, J. A. (1976). The regulation of nitrogen metabolism in Escherichia coli. In: Continuous Culture, vol. 6, Applications and New Fields, pp. 184-194. Edited by A. C. R. Dean, D. C. Ellwood, C. G. T. Evans \& J. Melling. London: Ellis Horwood/Society for Chemical Industry.

Kustu, S. G., McFarland, N. C., Hin, S. P., Esmon,
B. \& Ferro-Luzzi Ames, G. (1979). Nitrogen control in Salmonella typhimurium: coregulation of synthesis of glutamine synthetase and amino acid transport systems. Journal of Bacteriology 138, 218234.

LYNCH, J. M. \& HARPER, S. H. T. (1974). Formation of ethylene by a soil fungus. Journal of General Microbiology 80, 187-195.

Neussel, O. M. \& Tempest, D. W. (1979). The physiology of metabolite over-production. Symposia of the Society for General Microbiology 29, 53-82.

Powell, J. T. \& Morrison, J. F. (1978). The purification and properties of the aspartate aminotransferase and aromic amino acid aminotransferase from Escherichia coli. European Journal of Biochemistry 87, 391-400.

Primose, S. B. (1977). Evaluation of the role of methional, 2-keto 4-methiobutyric acid and peroxidase in ethylene formation by Escherichia coli. Journal of General Microbiology 98, 519-528.

Primose, S. B. (1979). Ethylene and agriculture: the role of the microbe. Journal of Applied Microbiology 46, $1-25$.

Sakamoto, N., Kotre, A. M. \& Savageau, M. A. (1975). Glutamate dehydrogenases from Escherichia coli : purification and properties. Journal of Bacteriology 124, 775-783.

Tanaka, H., Esaki, N. \& Soda, K. (1976). Purification and properties of methioninase from Pseudomonas ovalis. FEBS Letters 66, 307-311. 